\title{
Is phonological recoding under strategic control?
}

\author{
IAN DENNIS and STEPHEN E. NEWSTEAD \\ Plymouth Polytechnic, Plymouth PL4 8AA, England
}

\begin{abstract}
Two experiments are reported in which subjects were required to name the color in which letter strings were printed. In the first experiment, color-naming latencies were the same when the letter strings were pseudohomophones of color words (e.g., PINC) as when they were color names (e.g., PINK). Both these conditions produced slower responses than control strings matched with the pseudohomophones for visual similarity to the color word (e.g., PINN). Unlike the first experiment, the second included trials in which the ink color was congruent with the color to which the letter string was related. The results with incongruent stimuli paralleled those in the first experiment. With the congruent stimuli, however, responses were faster with color words than with either their pseudohomophones or control strings, which were equally slow. It is proposed that phonological recoding occurs relatively slowly but cannot be suppressed even when it harms performance.
\end{abstract}

There are a variety of convincing arguments to support the notion that users of alphabetic languages such as English can derive phonological codes from many word and nonword letter strings. For both words and nonwords, such phonological codes can be used, for example, in naming; in the case of words, they may under some circumstances be used in accessing the word's lexical entry. Much of the relevant evidence has been reviewed by Coltheart (1978), who has also concerned himself with the main theme of this paper: the extent to which the use of such phonological codes is under strategic control.

An experiment of Davelaar, Coltheart, Besner, and Jonasson (1978) provides evidence that reliance on a phonological code for lexical access may be reduced in a situation in which such reliance would impair performance. More specifically, Davelaar et al. employed a lexical decision paradigm in which the nature of the nonwords was systematically manipulated. In the first phase of the experiment, nonwords were all legal letter strings that did not sound like an English word (e.g., SLINT). In the second phase, all the nonwords did sound like English words (e.g., BRANE; nonwords of this sort will subsequently be referred to as pseudohomophones). In the presence of pseudohomophones, it would be expected that, if it were possible, subjects would make less use of phonological recoding since reliance on a phonological code would be likely to lead them to produce erroneous positive responses to pseudohomophones. Davelaar et al. were, in fact, able to demonstrate such a reduction in the use of phonological recoding. In the first phase, subjects took longer to respond to words that were the lower frequency members of homophonic pairs than to their nonhomophonic controls. This effect disappeared, however, in the second phase of the experiment, in which the nonwords were pseudohomophones. Thus it seems that reliance on phonological recoding in a lexical decision task is to some extent under strategic control.

However, this is clearly not the whole story. It is well established (e.g., Coltheart, Davelaar, Jonasson, \& Besner, 1977; Rubinstein, Lewis, \& Rubinstein, 1971) that when both pseudohomophones and nonwords that do not sound like words are used in a lexical decision task, subjects take longer to respond negatively to the pseudohomophones. Thus phonological recoding is clearly not totally abandoned in the presence of pseudohomophones. Moreover, it is not abandoned despite the fact that it leads to slower responses to pseudohomophones. Why should this be so? Two answers to this question seem possible. It may be that strategic control over reliance on phonological recoding is limited. Alternatively, it may be that, despite the fact that use of phonological recoding leads to slower responding to pseudohomophones, it has other compensating advantages. Thus, for example, it might lead to faster or more accurate responses to words or to nonwords that do not sound like words.

One way to determine whether subjects' control over the use of phonological recoding is limited is to see whether it continues to occur when it can only hinder performance. An experiment that appears to demonstrate that it does so is reported by Bakan and Alperson (1967). Bakan and Alperson employed the Stroop technique, in which subjects are required to name the color of the ink in which a letter string is printed. Color-naming latencies were longer for pronounceable nonword trigrams than for nonpronounceable ones. This seems to imply that subjects derived a phonological representation from the pronounceable trigrams, even though this was irrelevant to the task they were required to perform and led to longer color-naming 
latencies. However, the pronounceable and nonpronounceable trigrams also differed in terms of their visual similarity to English words. Thus, for example, there are no words that can be formed by changing a single letter in any of the four nonpronounceable trigrams (FJQ, RZQ, VGJ, and XFN) used by Bakan and Alperson, whereas at least one word and an average of six words can be formed by changing a single letter in the eight pronounceable trigrams (EKL, XAT, TUW, ZOJ, DAP, ISH, LAR, and FON) they used.

Results similar to those of Bakan and Alperson (1967) were obtained in a study by Guttentag and Haith (1978) in which subjects were required to name an outline picture that surrounded a letter string. Picturenaming latencies were longer when the letter string was a pronounceable nonword (e.g., LART) than when it was unpronounceable (e.g., $\mathrm{LBCH}$ ). Again, however, it may be visual similarity to English words that is crucial.

Closely related to these two experiments is a study reported by Gough and Cosky (1977) that again used the Stroop paradigm. The conditions used included one in which the letter string was the name of a color (e.g., GREEN) other than the ink color, one in which the letter string was a pseudohomophone of an incongruent color word (e.g., GRENE), and a third condition in which the letter string was another pronounceable nonword apparently with some visual similarity to a color word (e.g., GRAIF). The time taken to name ink color was shorter for the pronounceable nonword than for either color words or their pseudohomophones, but it did not differ between the latter two conditions. This result seems to imply that a phonological code is derived from the pseudohomophones of color words despite the fact that it impairs performance. Again, however, the interpretation of these results is complicated, since at least in some cases it seems that the color pseudohomophone was more visually similar to the base color word than its control was (GRENE looks more like GREEN than GRAIF does). A further difference between the color pseudohomophones and their controls was that the former were pseudohomophones and the latter were not. Hence it is logically possible that the difference in response latencies between these two conditions arises from some general consequences of pseudohomophony, such as the fact that there is a commonly used articulatory response corresponding to a pseudohomophone, rather than from an effect specific to color pseudohomophones.

An additional feature of the experiment of Gough and Cosky (1977) was that color-naming times were measured by determining the time required to name the colors of 25 letter strings in a list. Thus, naming latencies for individual letter strings could not be determined. It would seem desirable to have latencies for individual letter strings available for two reasons. First, it seems desirable to establish that the effects obtained are general to the types of letter string used rather than being due to the idiosyncratic properties of a few letter strings. Second, for reasons that will be dealt with in the discussion, it would seem useful to consider not only the mean reaction time in each condition, but also other aspects of its distribution.

For these reasons, it seems desirable to repeat the Gough and Cosky (1977) experiment. This was the aim of Experiment 1. The control words were matched with color pseudohomophones for visual similarity to the color word; naming latencies were measured separately for each stimulus, and, as a final control, the control words were also pseudohomophones, although not, of course, of color words.

\section{EXPERIMENT 1}

\section{Method}

Subjects. Twelve staff and student subjects of both sexes from Plymouth Polytechnic were recruited on a paid volunteer basis.

Materials. The letter strings used in this experiment were of three kinds (see Table 1 for a full list): (1) color words (e.g., GREEN, BLUE), (2) pseudohomophones of color words (e.g., GREAN, BLOO), and (3) controls (e.g., GREEF, BLIR). The control words change just as many letters from the original color word as do the pseudohomophones. Further, the controls are also pseudohomophones themselves.

The letter strings were printed in uppercase letters on black tachistoscope cards such that their height subtended an angle of approximately $.6 \mathrm{deg}$. Each string occurred once in each of the five incongruent colors. Thus GREEN occurred once each in blue, red, brown, pink, and white inks.

Procedure. Presentation was via an Electronic Developments two-field tachistoscope. Each trial began with an adaptation field consisting of four markers surrounding the region in which the letter string would appear. When ready, the subject initiated presentation by depressing a key that also started a timer; the subject's vocal response activated a voice key that stopped the timer and terminated the trial.

On arriving in the experimental cubicle, subjects were first instructed as to the appropriate names for each color. They were then familiarized with the task, using six practice items. These were the numbers $1,2,3$, and 4 printed in each of the six colors used in the experiment. If any subject was still unsure of the task, he was given the practice trials again.

The experiment itself involved 90 trials presented in a different random order for each subject. On each trial, the subject was presented with one of the colored letter strings and was instructed to name the color of the ink as quickly as possible. On the few occasions when the key failed to trigger, the letter string was re-presented at the end of the sequence. Responses given and naming latencies were recorded manually.

\section{Results and Discussion}

Mean response latencies for each letter string are given in Table 1. These means and the analyses to be reported are based on times for correct responses only.

The effect of letter string type was significant both across subjects $[F(2,22)=23.32, p<.001]$ and across words $[F(2,10)=14.05, p<.0025]$. Pairwise comparisons between the three types of letter string were carried out using the Newman-Keuls procedure, and they produced the same set of outcomes both across subjects and across words. Color-naming times were significantly 
Table 1

Mean Color-Naming Latencies (in Milliseconds) for Experiment 1

\begin{tabular}{llllll}
\hline \multicolumn{2}{c}{$\begin{array}{c}\text { Color } \\
\text { Names }\end{array}$} & \multicolumn{2}{c}{$\begin{array}{c}\text { Pseudohomophones } \\
\text { of Color Names }\end{array}$} & \multicolumn{2}{c}{$\begin{array}{c}\text { Control } \\
\text { Strings }\end{array}$} \\
\hline BLUE & 744 & BLOO & 727 & BLIR & 678 \\
RED & 752 & WRED & 697 & TRED & 690 \\
BROWN & 742 & BROUN & 754 & BRORN & 700 \\
GREEN & 749 & GREAN & 767 & GREEF & 696 \\
PINK & 740 & PINC & 737 & PINN & 700 \\
WHITE & 729 & WITE & 717 & HITE & 708 \\
Mean & 743 & & 733 & & 695 \\
\hline
\end{tabular}

longer with both color words and color pseudohomophones than with control strings $(\mathrm{p}<.01$ in both cases). However, color words and color pseudohomophones did not themselves differ in the latencies produced.

The number of errors was small and did not differ between conditions. Color words led to a total of six errors, color pseudohomophones to five, and control strings to eight. In total, these constitute $1.8 \%$ of the trials.

Our results clearly replicate those of Gough and Cosky (1977). It seems that subjects do derive a phonological code from the pseudohomophones of color words used in this experiment. What is more, the pseudohomophones of color words were just as disruptive to performance in the Stroop task as the color words themselves. On the basis of this result, we can reject the claim that use of the phonological code responsible for this effect is completely under strategic control; if it had been, then surely it would have been suppressed in this paradigm.

The outcome of Experiment 1 is somewhat disparate from that of a study by Naish (1980) that employed a modified version of the Stroop task in which subjects were required to sort cards bearing letter strings according to the color of the letter string. The types of letter string used included both color pseudohomophones and control strings matched to these color pseudohomophones for visual similarity to the base color word. The differences between the two types of letter string referred to above did not reach significance at the $5 \%$ level for either sex (although the females did show a strong trend toward longer sorting times for color pseudohomophones). It should be noted that the comparison of these conditions in Naish's experiment is complicated and perhaps rendered less powerful by the fact that for $20 \%$ of the cards in each pack, the ink color was congruent with the letter string, whereas it was incongruent for the remaining $80 \%$. It may be that results of the type obtained in Experiment 1 are specific to situations in which a vocal response is made. However, there are other explanations of the discrepancy, one of which will be discussed following the presentation of Experiment 2.

The difference in performance on color pseudohomophones and their controls found in the present experi- ment demonstrates that a phonological code is generated from them but leaves open the question of how this phonological code affects color-naming latency. The simplest possibility, although not the only one, is to suppose that the phonological representation derived from color pseudohomophones activates the lexical entry for the corresponding color name. The subsequent processes through which color pseudohomophones affect color-naming latency would then be the same as for color names themselves. Hence the suggestion is that phonological recoding is not under strategic control. How can this finding be reconciled with previous research that suggests the contrary?

One possibility is that the phonological code generated from color pseudohomophones in the present experiment only rarely activates a lexical entry but that on the few occasions when it does, the resulting response delay is much longer than that which arises when the lexical entry is activated by a visual code. The response delays in the two cases might differ because of the difference in the times the two types of code take to access the lexicon. This possibility is readily tested, since although occasional very long latencies to color pseudohomophones could give rise to a mean latency equal to that for color words, this would also lead to a larger variance of reaction time for color pseudohomophones. There was no evidence of such a difference in variance in the results of the present experiment.

A second way in which the present results might be reconciled with those of Davelaar et al. (1978) is to suppose that although subjects are unable to suppress the use of the phonological code, they may be able to regulate it in other ways. Thus, for example, they may be able to delay the arrival of this code until after the "yes" response to words in a lexical decision task has been initiated. Such a delay would be sufficient to eliminate the homophone effect in a lexical decision task, but not to prevent an effect of phonology on the relatively slow color-naming responses involved in the present experiment (and perhaps, also, it would not be sufficient to prevent the pseudohomophone effect in lexical decision).

A crucial feature of the foregoing speculations is the notion that the marked phonological effects that occur in Experiment 1 arise because the relatively long latencies involved in the Stroop paradigm allow time for a slow phonological code to arrive. If this is so, then in an analogous experimental situation in which the response latencies are shorter, pseudohomophones should no longer produce results similar to those that color words produce. This prediction was tested in Experiment 2 by including conditions in which the letter string was derived from a color name matching the color in which the string was printed. Such congruent combinations are known to produce faster color-naming responses than control words having no relationship to color (DalrympleAlford, 1972) or, sometimes, than meaningless symbols (Dyer, 1971). 


\section{EXPERIMENT 2}

\section{Method}

Subjects. Eighteen staff and student subjects of both sexes from Plymouth Polytechnic were paid for their participation in this experiment.

Materials and Procedure. The same color words, color pseudohomophones, and controls used in Experiment 1 were used. Each letter string occurred six times, three times in its congruent color (e.g., GREEN colored green) and three times in different incongruent colors. Incongruent colors were chosen such that all six colors occurred an equal number of times There were a total of 108 trials, congruent and incongruent stimuli of all three types being mixed in a different random sequence for each subject. Details of stimulus preparation, tachistoscopic presentation, and response timing paralleled those of Experiment 1.

\section{Results and Discussion}

Mean latencies for each condition are given in Table 2. Randomized-block factorial analyses of variance were carried out over both subjects and words. Both these analyses revealed faster responses to congruent than to incongruent stimuli [over subjects, $\mathrm{F}(1,17)=100.7$, $\mathrm{p}<.001$; over words, $\mathrm{F}(1,5)=100.9, \mathrm{p}<.001]$ and $\mathrm{a}$ significant interaction between this factor and type of letter string [over subjects, $F(2,34)=9.26, p<.001$; over words, $F(2,10)=9.44, p<.005]$. Tests of simple main effects showed significant effects of the type of letter string for both congruent stimuli [over subjects, $F(2,68)=3.82, p<.05 ;$ over words, $F(2,20)=3.90$, $p<.05$ ] and incongruent stimuli [over subjects, $F(2,68)$ $=5.23, \mathrm{p}<.01 ;$ over words, $\mathrm{F}(2,20)=6.44, \mathrm{p}<.01]$. Each of these simple main effects was further investigated using Newman-Keuls multiple-comparison tests.

For incongruent stimuli, the outcome of these tests broadly parallels the results of Experiment 1 . There was

Table 2

Mean Times to Name Ink Color (in Milliseconds) and Numbers of Errors in Experiment 2

\begin{tabular}{|c|c|c|c|c|c|}
\hline \multicolumn{2}{|c|}{$\begin{array}{l}\text { Color } \\
\text { Names }\end{array}$} & \multicolumn{2}{|c|}{$\begin{array}{c}\text { Pseudohomophones } \\
\text { of Color Names }\end{array}$} & \multicolumn{2}{|c|}{$\begin{array}{l}\text { Control } \\
\text { Strings }\end{array}$} \\
\hline \multicolumn{6}{|c|}{ Incongruent Stimuli } \\
\hline BLUE & 850 & BLOO & 830 & BLIR & 765 \\
\hline RED & 829 & WRED & 802 & TRED & 799 \\
\hline BROWN & 800 & BROUN & 766 & BRORN & 754 \\
\hline GREEN & 804 & GREAN & 849 & GREEF & 810 \\
\hline PINK & 848 & PINC & 817 & PINN & 807 \\
\hline WHITE & 813 & WITE & 792 & HITE & 788 \\
\hline Mean & 825 & & 809 & & 787 \\
\hline Errors & 13 & & 15 & & 7 \\
\hline \multicolumn{6}{|c|}{ Congruent Stimuli } \\
\hline BLUE & 648 & BLOO & 701 & BLIR & 680 \\
\hline RED & 638 & WRED & 674 & TRED & 672 \\
\hline BROWN & 665 & BROUN & 672 & BRORN & 718 \\
\hline GREEN & 652 & GREAN & 659 & GREEF & 668 \\
\hline PINK & 619 & PINC & 668 & PINN & 633 \\
\hline WHITE & 615 & WITE & 629 & HITE & 643 \\
\hline Mean & 640 & & 667 & & 669 \\
\hline Errors & 0 & & 2 & & 0 \\
\hline
\end{tabular}

no significant difference in color-naming latency between color words and their pseudohomophones. Control strings produced significantly shorter color-naming latencies than both color words $(\mathrm{p}<.05$ over subjects, $p<.01$ over words) and color pseudohomophones ( $p<.10$ over subjects, $p<.05$ over words), although the latter difference fell slightly short of conventional significance levels over subjects.

For congruent stimuli, color words produced shorter color-naming latencies than either their pseudohomophones ( $p<.05$ over both subjects and words) or control strings $(p<.05$ over both subjects and words). There was, however, no significant difference between color pseudohomophones and control strings in this respect.

Thus, for congruent stimuli, there is no evidence of any influence of a phonological code on performance. This is consistent with the suggestion made previously that this code operates relatively slowly and is able to affect response latency only when the response is sufficiently slow.

The congruent conditions of Experiment 2 are closely related to those used by Rayner and Posnansky (1978). They used a task in which subjects were required to name a picture on which a letter string was superimposed, and in two experiments (Experiments 5 and 6), they included pseudohomophones of the picture name among the letter strings used. The results of these experiments indicate that, at least with sufficiently long exposure durations, picture-naming times were shorter when the letter string preserved the phonemic characteristics of the picture name than when it did not. This feature of the result would appear to be in conflict with the failure to find any difference between color pseudohomophones and control words in the congruent conditions of Experiment 2. The most likely reason for this discrepancy is the fact that the different types of letter string were randomly mixed in Experiment 2, whereas they were blocked in the experiments of Rayner and Posnansky. This blocking creates the possibility that in a sequence of trials in which the letter string is always a pseudohomophone of the picture label, subjects may name the letter string rather than the picture. Thus any apparent facilitating effect of pseudohomophones under these conditions might merely indicate that subjects can name nonword letter strings when it is advantageous to do so. The fact that congruent and incongruent trials are randomly mixed precludes the use of any similar strategy in Experiment 2.

It should also be noted that even for control strings the simple main effect of congruency was both large and significant [over subjects, $\mathrm{F}(1,51)=46.1, \mathrm{p}<.001$; over words, $F(1,15)=52.8, p<.001]$. These control strings still have considerable visual and phonological similarity to the color words from which they are derived. It is not, therefore, surprising that they can slow the naming of incongruent colors or speed up the naming of congruent colors or both. It is of interest, how- 
ever, that the magnitude of this effect is larger than the differences between different types of incongruent or congruent letter strings. It seems that only moderate similarity to a color word is necessary for a letter string to produce powerful effects in this paradigm.

The visual similarity that both the control strings and the color pseudohomophones have to color words may be of considerable importance to the phenomena reported here. It is proposed that the phonological code derived from color pseudohomophones has an effect on the incongruent condition but not on the congruent condition because the response is delayed in the former case and facilitated in the latter. But what is the initial cause of these delays and facilitations when the letter string is a color pseudohomophone rather than a color word? It seems likely that the visual similarity of color pseudohomophones to color words is the original cause of these effects and that a phonological effect is then superimposed on this in the incongruent condition. If this is so, then a prerequisite for obtaining effects of the sort reported here in the incongruent condition may be that the visual similarity of the color pseudohomophone to the color word should create an initial delay sufficient to allow the phonological code to have an effect. As Naish (1980) points out, the version of the Stroop test in which colors are named aloud always demonstrates a larger interference effect than do those in which card-sorting or button-pressing responses are used. This, then, may be the reason why there was no significant difference between color pseudohomophones and controls in Naish's experiment.

\section{GENERAL DISCUSSION}

The results of Experiment 1 and the incongruent condition of Experiment 2 demonstrate that subjects derived a phonological code from letter strings used in a Stroop task despite the fact that these letter strings were irrelevant to the task the subjects were asked to perform and the phonological code harmed performance. However, there were no phonological effects on the much faster responses to congruent stimuli in Experiment 2 . Although these results are susceptible to a variety of explanations, it is convenient to take as a starting point in considering these alternatives an account that has the virtues of both simplicity and consistency with existing theory. This account supposes, in line with existing accounts of the Rubinstein pseudohomophone effect (e.g., Coltheart et al., 1977), that pseudohomophones can access the lexical entries of the corresponding words and that this provides the mechanism through which color pseudohomophones can give rise to a Stroop effect. It further assumes that the phonological code through which pseudohomophones activate the related lexical entry is generated automatically. That is, it is generated even when it can only impair performance. This is a sufficient explanation of why subjects generate a phonological code in a lexical decision task despite the fact that it slows their responses to pseudohomophones. In order to explain the fact that color pseudohomophones did not produce faster responses to congruent stimuli in Experiment 2, it is supposed that visual access to the lexicon occurs faster than phonological access, so that the response has been determined before phonological access occurs, and thus, the phonological properties of the letter string cannot influence response latency. This, again, is an assumption that has been widely made for other reasons (e.g., Baron \& McKillop, 1975; Coltheart et al., 1977, Stanovich \& Bauer, 1978).

Despite some attractions, the foregoing account is perhaps overly simple, in that it rests on the implicit assumption of a unitary lexicon from which all aspects of word knowledge are retrieved. The alternative explanations that become available when this assumption is discarded may be illustrated by reference to the account of the Stroop effect provided by Stirling (1979). Stirling proposes that there are two components of Stroop interference. The first component arises because the ink color and the color word access different semantic codes and a choice between these must be made so that the response can be made to the ink color. The second component arises in a system, such as the output logogens in Morton's (1979) revised model, for making spoken responses available (this could be regarded as a lexicon storing sets of articulatory instructions). Interference at this level arises because entries related both to the ink color and to the letter string become activated. The entries corresponding to the color words used as responses will be in a state of perpetual priming due to the repeated utterance of these words. Hence the interference will be greater when the letter string activates an entry that corresponds to a member of the response set than when it activates some other entry. The interference effect obtained with color pseudohomophones might involve either or both of these components. If the first component is involved, then the phonological code derived from color pseudohomophones by some process of spelling-to-sound conversion must provide access to the meaning of the corresponding color word. Alternatiyely, it is possible that the interference obtained with color pseudohomophones occurs without any access to the meaning of the color word. This could occur if the phonological code derived from color pseudohomophones could directly access the system from which articulatory specifications are retrieved.

While aspects of the process by which color pseudo. homophones give rise to Stroop interference remain uncertain, two conclusions seem inescapable. First, it is necessary to suppose the existence of a spelling-tosound conversion process by which a phonological code is derived from the color pseudohomophones. Second, this process continues to operate even when its effects can only be detrimental to performance. 


\section{REFERENCES}

Bakan, P., \& Alperson, B. Pronounceability, attensity and interference in the color word test. American Journal of Psychology, 1967, 80, 416-420.

BAron, J., \& McKillop, B. J. Individual differences in speed of phonemic analysis, visual analysis and reading. Acta Psychologica, 1975, 39, 91-96.

Coltheart, M. C. Lexical access in simple reading tasks. In G. Underwood (Ed.), Strategies of information processing. London: Academic Press, 1978.

Coltheart, M., Davelaar, E., Jonasgon, J. T., \& Besner, D. Access to the internal lexicon. In S. Dornic (Ed.), Attention and performance VI. Hillsdale, N.J: Erlbaum, 1977.

Dalrymple-Alford, E. C. Associative facilitation and interference in the Stroop color-word task. Perception \& Psychophysics, 1972, 11, 274-276.

Davelaar, E., Coltheart, M., Besner, D., \& Jonasson, J. T. Phonological recoding and lexical access. Memory \& Cognition, $1978,6,391-402$.

DYE R, F. N. The duration of word meaning responses: Stroop interference for different pre-exposures of the word. Psychonomic Science, 1971, 25, 229-231.

Govar, P. B., \& Cosky, M. L. One second of reading again. In J. N. Castellan, D. B. Pisoni, \& G. R. Potts (Eds.), Cognitive theory (Vol. 2). Hillsdale, N.J.: Erlbaum, 1977.
Guttentag, R. E., \& Haith, M. M. Automatic processing as a function of age and reading ability. Child Development, 1978, 49, 707-716.

MoRTon, J. Facilitation in word recognition: Experiments causing change in the logogen model. In P. A. Kolers, M. E. Wrolstad, \& H. Bouma (Eds.), Processing of visible language. New York: Plenum, 1979.

Narsk, P. Phonological recoding and the Stroop effect. British Journal of Psychology, 1980, 71, 395-400.

Rayner, K., \& Posnangky, C. Stages of processing in word identification. Journal of Experimental Psychology: General, 1978, 107, 64-80.

Rubingtein, H., Lewis, S. S., \& Rubinstein, M. A. Evidence for phonemic recoding in word recognition. Journal of Verbal Learning and Verbal Behavior, 1971, 10, 647-657.

Stanovich, K. W., Bauzn, D. W. Experiments on the spelling to sound regularity effect in word recognition. Memory \& Cognition, 1978, 6, 410-415.

Stirlina, N. Stroop interference: An input and an output phenomenon. Quarterly Journal of Experimental Psychology, 1979, 31, 121-132.

(Received for publication October 24, 1980; revision accepted February 23, 1981.) 